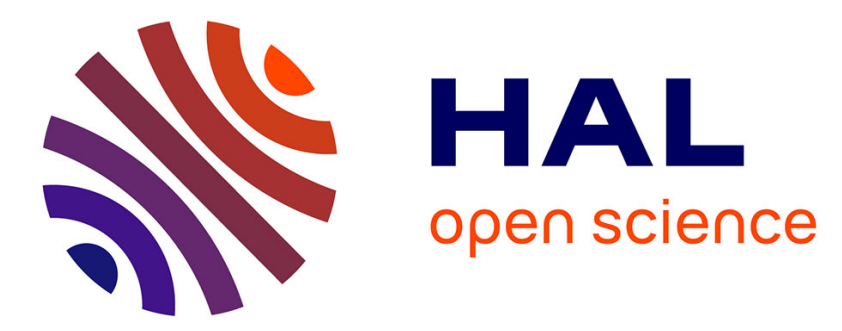

\title{
Integration of grating couplers with a compact photonic crystal demultiplexer on an InP membrane
}

Tiziana Stomeo, Frederick van Laere, Melanie Ayre, Cyril Cambournac, Henri Benisty, Dries van Thourhout, Roel Baets, T.F. Krauss

\section{- To cite this version:}

Tiziana Stomeo, Frederick van Laere, Melanie Ayre, Cyril Cambournac, Henri Benisty, et al.. Integration of grating couplers with a compact photonic crystal demultiplexer on an InP membrane. Optics Letters, 2008, 33, pp.884-886. hal-00814518

\section{HAL Id: hal-00814518 \\ https://hal-iogs.archives-ouvertes.fr/hal-00814518}

Submitted on 16 Jul 2013

HAL is a multi-disciplinary open access archive for the deposit and dissemination of scientific research documents, whether they are published or not. The documents may come from teaching and research institutions in France or abroad, or from public or private research centers.
L'archive ouverte pluridisciplinaire HAL, est destinée au dépôt et à la diffusion de documents scientifiques de niveau recherche, publiés ou non, émanant des établissements d'enseignement et de recherche français ou étrangers, des laboratoires publics ou privés. 


\title{
Integration of grating couplers with a compact photonic crystal demultiplexer on an InP membrane
}

\author{
Tiziana Stomeo, ${ }^{1, *}$ Frederik Van Laere ${ }_{2}^{2}$ Melanie Ayre, ${ }^{3}$ Cyril Cambournac, ${ }_{1}^{3}$ Henri Benisty, ${ }^{3}$ \\ Dries Van Thourhout, ${ }^{2}$ Roel Baets, ${ }^{2}$ and Thomas F. Krauss ${ }^{1}$ \\ ${ }^{1}$ School of Physics and Astronomy, University of St. Andrews, Fife KY16 9SS, UK \\ ${ }^{2}$ Department of Information Technology (INTEC), Ghent University-Interuniversitary Microelectronics Center (IMEC), \\ B-9000 Ghent, Belgium \\ ${ }^{3}$ Laboratoire Charles Fabry de l'Institut d'Optique, CNRS, Campus Polytechnique, Universite Paris-Sud, \\ RD 128, F-91127 Palaiseau, France \\ *Corresponding author: tiziana.stomeo@unile.it
}

Received January 23, 2008; revised March 12, 2008; accepted March 13, 2008; posted March 17, 2008 (Doc. ID 91962); published April 14, 2008

\begin{abstract}
We demonstrate the integration of a $30 \%$ efficient grating coupler with a compact photonic crystal wavelength demultiplexer (DeMUX). The DeMUX has seven output channels that are spaced $10 \mathrm{~nm}$ apart and is aimed at coarse WDM applications. The integrated devices are realized on a high-index-contrast InP membrane using a simple benzocyclobutene wafer bonding technique. Cross talks of -10 to $-12 \mathrm{~dB}$ for four channels $20 \mathrm{~nm}$ apart are obtained without optimization. (C) 2008 Optical Society of America

OCIS codes: $050.5298,130.0130,130.5296$.
\end{abstract}

Compact integration of optical functions on a chip is a key driver to provide low-cost optoelectronic devices that are needed in metropolitan optical networks. High refractive index contrast materials and planar photonic crystal $(\mathrm{PhC})$ technology enable the largescale integration of optical functions, since waveguides, bends, and core integrated elements can be very compact. Many recent examples of exploiting a large refractive index contrast are provided by silicon-on-insulator (SOI) structures [1-3] and III-V materials in membrane configuration [4]. The SOI platform, is very well suited for performing passive functionality, but it is still rather elusive to achieve active functionality on $\mathrm{Si}$, owing to its indirect bandgap. An emerging solution is to heterogeneously integrate III-V material (active functions) and SOI (passive functions) [5], placing high demands on both. Another solution is to use indium phosphide ( $\mathrm{InP}$ ) compounds, which have been a workhorse for implementing photonic devices with various active functions, such as photodetection, tunability, and carrier injection for gain and lasing. Since such an integration is especially relevant to frequency-selective devices, we use this approach, rather than $\mathrm{Si}$, as the platform for our investigation. Namely, we use a simple benzocyclobutene (BCB) wafer bonding technique [6] to realize InP-membrane-type devices. Using this approach, we present the integration of an efficient grating coupler with a very compact $\mathrm{PhC}$ wavelength demultiplexer (De MUX) that operates in the 1500-1560 nm wavelength range.

The one-dimensional (1D) grating coupler $(12 \mu \mathrm{m}$ $\times 12 \mu \mathrm{m})$ implemented here on top of an Au mirror can achieve a coupling efficiency from standard single-mode fiber to membrane-based waveguides of $\sim 56 \%[7,8]$ with relaxed alignment tolerances and relatively large bandwidth. The DeMUX is a membrane version of the device already described in [9-12] for conventional InP heterostructures. It exploits energy transfer caused by intermodal coupling at mini-stop-bands (MSBs) [13,14] of a multimode $\mathrm{PhC}$ waveguide. When polychromatic light impinges along the axis of such a waveguide, it essentially feeds the transverse fundamental mode at all frequencies. But, as it experiences propagation along the periodic $\mathrm{PhC}$ waveguide, this fundamental mode is coupled to a higher-order mode only for the frequency range within the MSBs. The generated signal, i.e., the WDM signal of interest, is then efficiently and directionally extracted by thinning one of the $\mathrm{PhC}$ walls to a few rows. The wavelength selectivity is introduced by varying the central frequency of the MSB, which, in practice, relies on tuning (stepwise or continuously) the $\mathrm{PhC}$ waveguide width along the guide.

A typical layout is shown in Fig. 1(a). The $\mathrm{PhC}$ waveguide is defined by removing five rows of holes

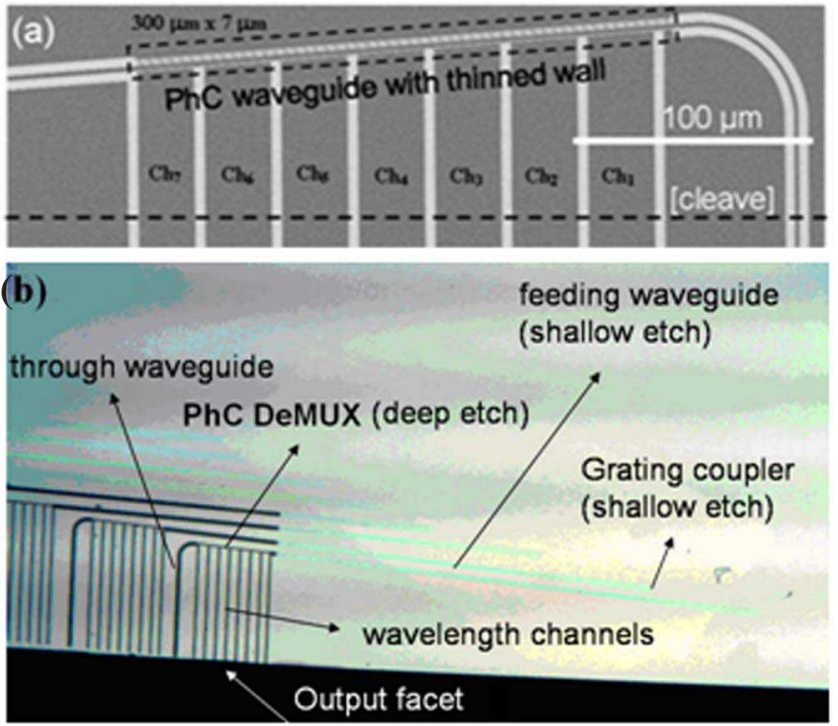

Fig. 1. (Color online) (a) Layout of the PhC DeMUX with seven output channels. (b) Overall test circuit comprising shallow-etched grating and PhC DeMUX, flip chipped and BCB bonded to a host substrate. 
("W5") along the $\Gamma \mathrm{K}$ direction, with the $\mathrm{PhC}$ cladding on one side thinned down to two rows of holes to extract the higher-order mode. For each channel, a section of $\sim 30 \mu \mathrm{m}$ in length is sufficient for good extraction, which results in a compact device that successfully compares to, e.g., the approaches of [15-17]. The $\mathrm{PhC}$ period is $540 \mathrm{~nm}$, and the filling factor is $41 \%$.

Experimentally, we used a heterostructure consisting (from top to bottom) of a $300 \mathrm{~nm}$ InP-membrane layer, a $400 \mathrm{~nm}$ InGaAsP etch-stop layer, a $300 \mathrm{~nm}$ InP etch-stop layer, and a $400 \mathrm{~nm}$ InGaAsP etch-stop layer on an InP substrate. All the etch-stop layers are sacrificial and are removed in the membraning-BCB bonding process. We used a heterostructure with multiple etch-stop layers, although simpler designs are possible. The essential part of the heterostructure is the $300 \mathrm{~nm} \mathrm{InP}$ guide layer followed by a 400-600 nm (in our case, $522 \mathrm{~nm}$ ) thick InGaAs etchstop layer. A noteworthy challenge is that the $1 \mathrm{D}$ grating coupler requires shallow etching $(\sim 90 \mathrm{~nm}$ deep), whereas the wavelength-selective DeMUX has to be deeply etched $(\sim 300 \mathrm{~nm}$ completely through the membrane layer). To avoid alignment errors, both the coupler and the DeMUX are written in a single step using a Raith Elphy $e$-beam lithography tool. After $e$-beam writing in ZEP520-A positive resist and pattern transfer into the $\mathrm{SiO}_{2}$ hard mask using reactive ion etching (RIE) with $\mathrm{F}$ chemistry, a window is opened by optical lithography to etch the DeMUX first completely through the InP membrane $(300 \mathrm{~nm})$. During the first InP etch, the grating coupler and the waveguide are covered with photoresist. The photoresist is then removed, and the whole pattern is etched further to a depth of $90 \mathrm{~nm}$. This means that the DeMUX is etched slightly into the first InGaAsP etchstop layer. Since this layer will be removed later, however, this is of no consequence. Scanning electron microscope (SEM) pictures of the sample prior to bonding are shown in Fig. 2. A high-quality grating coupler (period of $660 \mathrm{~nm}$ and duty cycle of 50\%) and $\mathrm{PhC}$ DeMUX (hole diameter of $362 \mathrm{~nm}$ ) with wellcontrolled sizes were achieved after the pattern is transferred to the InP layer. In the next step, a BCBbuffer layer is spin coated onto the InP die, and $\mathrm{Au}$ is deposited opposite the grating couplers. The die is then bonded onto a GaAs host substrate (with another BCB layer), aligning the cleaving planes of both substrates [6]. We chose GaAs as the host substrate in the BCB bonding process to facilitate facet cleaving, although other substrates such as SOI or Si are equally suitable. After curing of the $\mathrm{BCB}$, the InP substrate is removed using lapping and wet etching. Finally, all three etch-stop layers are wet etched, the $\mathrm{BCB}$ is removed from the holes by inductively coupled plasma (ICP) etching to obtain air holes, and an output facet is cleaved [see optical image in Fig. $1(\mathrm{~b})]$.

To test the integrated device, a single-mode input fiber connected to a tunable laser is positioned at $10^{\circ}$ off the vertical axis above the grating to avoid reflections [7]. The 1D grating couples the light into the

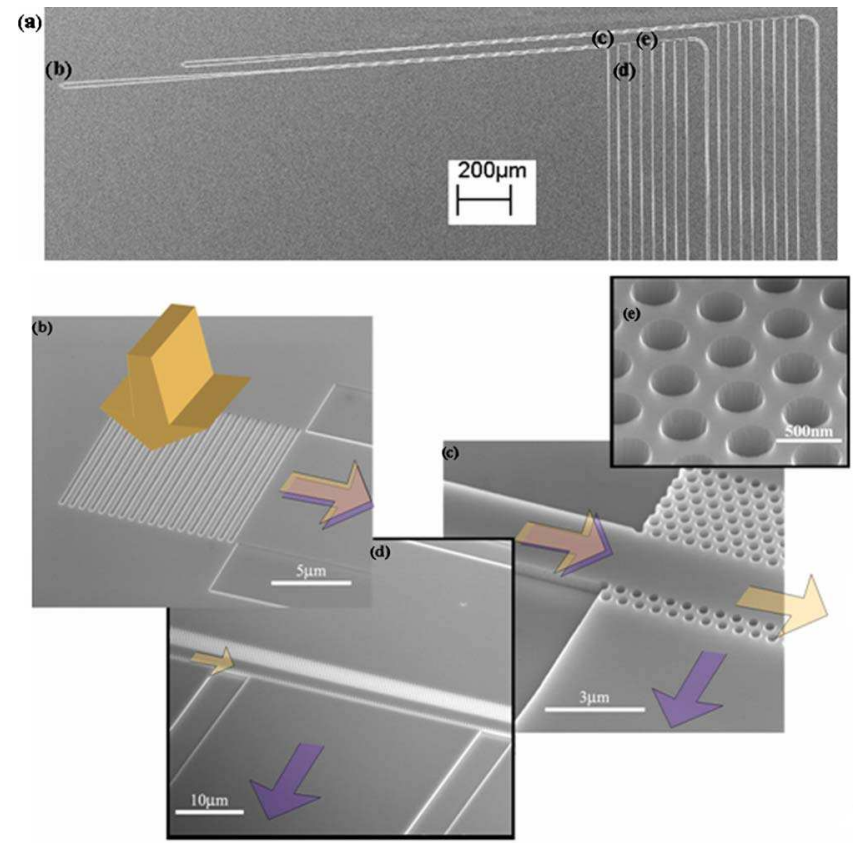

Fig. 2. (Color online) SEM pictures of the devices prior to bonding. (a) Complete device layout: 1D grating coupler integrated with the PhC DeMUX. (b) Input grating coupler (shallow etch). (c) Entrance of the $\mathrm{PhC}$ waveguide. (d) Single-channel view. (e) $\mathrm{PhC}$ holes (deep etch).

membrane waveguide from where it feeds into the $\mathrm{PhC}$ demultiplexer. The optical signal in the seven channels, ranging from 1500 to $1560 \mathrm{~nm}$, is collected at the output facet using a microscope objective lens and measured with a detector. One channel is measured at time while scanning the laser frequency. The demultiplexing operation of the $\mathrm{PhC}$ device can clearly be seen in Fig. 3(b). The $Q$ factor obtained for the extracted signals as well as the uniform channel spacing of $10 \mathrm{~nm}$ are close to those designed. The output signals are normalized to the input grating coupler spectrum determined from a fiber-to-fiber reference measurement on the same sample [see Fig. $3(\mathrm{a})$. The cross talk of the device is -8 to $-12 \mathrm{~dB}$ for channels spaced by $20 \mathrm{~nm}$. Between adjacent channels (10 $\mathrm{nm}$ spacing) it raises up to $-4 \mathrm{~dB}$ instead of the theoretically predicted value of $-7.5 \mathrm{~dB}$. Improvement should result from engineering the transfer function of the MSB, e.g., through fine tuning the size and number of holes of the PhC cladding through which the signal is extracted. Figure 3(c) shows the corresponding coupled-mode modeling [12], which reproduces very well all the spectral details related to the succession of shifted MSBs, for example, the kinks and shoulders of the rightmost channel spectrum. The basis towards further optimization is thus clearly given and hinges on modestly reducing losses and optimizing the section lengths for each channel.

In conclusion, we have demonstrated the integration of two very distinct passive structures on a bonded InP membrane. We combined a shallowetched 1D grating coupler with a deeply etched $\mathrm{PhC}$ DeMUX for operation at the $1500-1560 \mathrm{~nm}$ wavelength window. We achieved a good separation of seven optical channels with a spectral resolution of 


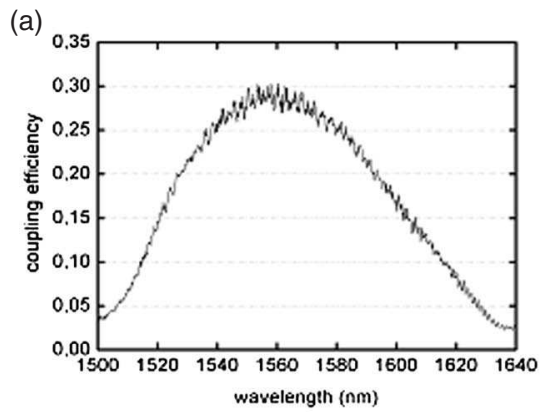

(b)

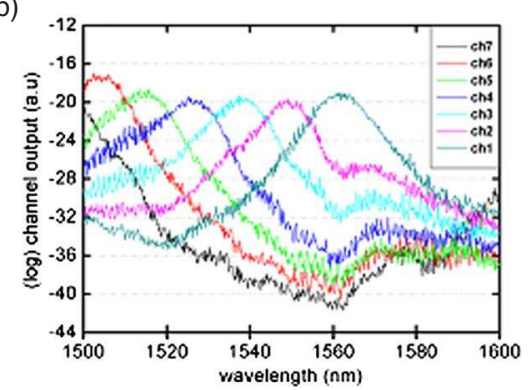

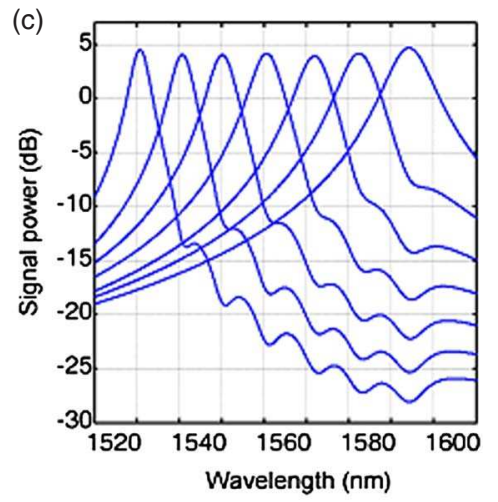

Fig. 3. (Color online) (a) Grating coupler spectrum control. (b) Channel output normalized to the grating coupler spectrum. (c) Coupled-mode theory modeling rendering most spectral details.

$10 \mathrm{~nm}$ and $-4 \mathrm{~dB}$ cross talk, or four channels suitable for coarse WDM (CWDM) at $20 \mathrm{~nm}$ spacing with a cross talk of -10 to $-12 \mathrm{~dB}$. The typical -10 to $-12 \mathrm{~dB}$ cross talk for the CWDM $20 \mathrm{~nm}$ spacing (every other channel here) can be further improved, all the more because the coupled-mode theory underlying the demultiplexing operation seems fully validated for this first implementation on a membrane. We thus demonstrate a remarkable combination of a nanophotonic strong-index contrast technology and of a design exploiting modes at such a mesoscopic scale that applicability of a revisited coupled-mode approach is granted. This extension of tools that have proven so beneficial to traditional integrated optics in the past and today, in one of the most compact embodiments for demultiplexing [16-18], clearly fosters the perspectives of nanophotonic approaches toward devices of the real world. Along this line, further extension of this work to include detectors and emitters is readily possible, given the InP-based material used in our experiments.

This work is carried out within the framework of the European project FUNFOX under grant IST004582.

\section{References}

1. M. Loncar, T. Doll, J. Vuckovic, and A. Scherer, J. Lightwave Technol. 18, 1402 (2000).

2. I. Marki, M. Salt, H. P. Herzig, R. Stanley, L. El Melhaoui, P. Lyan, and J. M. Fedeli, Opt. Lett. 31, 513 (2006).

3. Y. Akahane, T. Asano, B. S. Song, and S. Noda, Opt. Express 13, 1202 (2005).

4. A. Xing, M. Davanco, D. J. Blumenthal, and E. L. Hu, J. Vac. Sci. Technol. B 22, 70 (2004).

5. H. T. Hattori, C. Seassal, E. Touraille, P. Rojo-Romeo, X. Letartre, G. Hollinger, P. Viktorovitch, L. Di Cioccio,
M. Zussy, L. El Melhaoui, and J. M. Fedeli, IEEE Photon. Technol. Lett. 18, 223 (2006).

6. G. Roelkens, J. Brouckaert, D. Van Thourhout, R. Baets, R. Notzel, and M. Smit, J. Electrochem. Soc. 153, G1015 (2006).

7. D. Taillaert, F. Van Laere, M. Ayre, W. Bogaerts, D. VanThourhout, P. Bienstman, and R. Baets, Jpn. J. Appl. Phys. Part 1 45, 6071 (2006).

8. F. Van Laere, G. Roelkens, M. Ayre, J. Schrauwen, D. Taillert, D. Van Thourhout, T. F. Krauss, and R. Baets, J. Lightwave Technol. 25, 151 (2007).

9. E. Viasnoff-Schwoob, C. Weisbuch, H. Benisty, C. Cuisin, E. Derouin, O. Drisse, G. H. Guan, L. Legouezigou, O. Legouezigou, F. Pommereau, S. Golka, H. Heidrich, H. J. Hensel, and K. Janiak, Appl. Phys. Lett. 86, 101107 (2005).

10. L. Martinelli, H. Benisty, O. Khayam, G. H. Duan, H. Heidrich, and K. Janiak, J. Lightwave Technol. 25, 2385 (2007).

11. L. Martinelli, H. Benisty, O. Drisse, E. Derouin, F. Pommereau, O. Legouezigou, and G. H. Duan, IEEE Photon. Technol. Lett. 19, 282 (2007).

12. M. Ayre, C. Cambournac, H. Benisty, O. Khayam, H. Benisty, T. Stomeo, and T. F. Krauss, Photonics Nanostruct. Fundam. Appl. 6, 19 (2008).

13. S. Olivier, H. Benisty, C. Weisbuch, C. J. Smith, T. F. Krauss, and R. Houdré, Opt. Express 11, 1490 (2003).

14. S. Olivier, M. Rattier, H. Benisty, C. J. M. Smith, R. M. De La Rue, T. F. Krauss, U. Oesterle, R. Houdré, and C. Weisbuch, Phys. Rev. B 63, 113311 (2001).

15. T. Niemi, L. H. Frandsen, K. K. Hede, A. Harpoth, P. I. Borel, and M. Kristensen, IEEE Photon. Technol. Lett. 18, 226 (2006).

16. Y. Akahane, T. Asano, H. Takano, B.-S. Song, Y. Takana, and S. Noda, Opt. Express 13, 2512 (2005).

17. J. Brouckaert, W. Bogaerts, P. Dumon, D. Van Thourhout, and R. Baets, J. Lightwave Technol. 25, 1269 (2007).

18. W. Lijun, M. Mazilu, T. Karle, and T. F. Krauss, IEEE J. Quantum Electron. 38, 915 (2002). 